\title{
Prevention of Auditory Dysfunction in Hypothyroid Tshr Mutant Mice by Thyroxin Treatment During Development
}

\author{
Pamela M. Sprenkle, ${ }^{1,2,4}$ JoAnn McGee, ${ }^{1-3}$ John M. Bertoni, ${ }^{2,4}$ And Edward J. Walsh ${ }^{1-3}$ \\ ${ }^{1}$ Developmental Auditory Physiology Laboratory, Boys Town National Research Hospital, Omaha, NE 68131, USA \\ ${ }^{2}$ Department of Biomedical Sciences, Creighton University, Omaha, NE 68178, USA \\ ${ }^{3}$ Department of Otolaryngology, Creighton University, Omaha, NE 68178, USA \\ ${ }^{4}$ Department of Neurology, Creighton University, Omaha, NE 68178, USA
}

Received: 11 September 2000; Accepted: 11 April 2001; Online publication: 1 August 2001

\begin{abstract}
Based on previous work, it is clear that genetically hypothyroid $T s h r^{\text {hyt }}$ mutant mice are congenitally deaf [O'Malley et al. (1995) Hear. Res. 88: 181-189, Sprinkle et al. 2001b, J. Assoc. Res. Otolaryngol. DOI: $10.1007 / \mathrm{s} 101620010077]$. However, the extent to which auditory development is dependent on the availability of thyroxin $\left(\mathrm{T}_{4}\right)$ during specific developmental stages is unknown. The aim of this study was to determine the relative importance of prenatal and postnatal thyroxin on the ontogeny of hearing in the hyt mouse. Experimental hypothyroid subjects were offspring of hyt/hyt breeders implanted with $\mathrm{T}_{4}$ or placebo controlled-release pellets 14 days prior to mating. Pups received $\mathrm{T}_{4}$ or saline placebo injections from birth through postnatal day 14 (P14) or the time of testing on P28. In the absence of exogenous $\mathrm{T}_{4}$ replacement, very high stimulus levels ( $>80 \mathrm{~dB}$ SPL) were required to elicit responses. Remarkably, $\mathrm{T}_{4}$ treatment confined to the postnatal period failed to significantly improve auditory function relative to untreated animals, while response thresholds, latencies, and amplitudes of mice born to dams that received $\mathrm{T}_{4}$ during pregnancy were significantly improved relative to both of the untreated groups. Response thresholds were improved somewhat when maternal $\mathrm{T}_{4}$ replacement was followed by treatment during the first 14 days of life, and animals treated throughout prenatal and postnatal life were
\end{abstract}

Correspondence to: Edward J. Walsh Ph.D - Boys Town National Research Hospital 555 North 30th Street • Omaha, NE 68131. Telephone: (402) 498-6701; fax: (402) 498-6351; email: walsh@boystown.org comparable to those of age-matched euthyroid individuals. Findings from this study show that treatment of hyt/hyt mice with exogenous $\mathrm{T}_{4}$ significantly attenuates hypothyroid-induced otopathology in a developmental-stage-dependent manner. In addition, we demonstrate that postnatal development is critically dependent on prenatal exposure to thyroxin and that the critical window of $T_{4}$ dependence extends throughout development.

Keywords: hypothyroidism, development, hearing, deafness, maturation, thyrotropin

\section{INTRODUCTION}

It is generally understood that the severity of hypothyroidism-induced impairment of auditory system development in mammals is proportional to the onset and duration of thyroid hormone deficiency. When initiated in a mature animal, thyroid hormone deficiency generally produces a mild form of otopathology that is typically responsive to thyroxin $\left(\mathrm{T}_{4}\right)$ replacement therapy (Deol 1973; Hébert et al. 1985a, b). Hypothyroidism arising early in development, on the other hand, characteristically produces more severe auditory deficits that are typically refractory to replacement therapy (Deol 1973; Meyerhoff 1979; Uziel et al. 1983, 1985; Hébert et al. 1985a, b). The main body of existing data suggests that the auditory system is most sensitive to thyroid hormones from the beginning of autonomous secretion through the age that the first responses to airborne sounds can be elicited (Deol 1973; Hébert et al. 1985b). In rodents, as in most 
altricious mammals, autonomous secretion begins late in the prenatal period (Jacobson and Brent 1959; van Heyningen 1961) and the first responses to airborne sounds occur between postnatal days 9 and 14 (Alford and Ruben 1963; Mikaelian and Ruben 1965; Ehret 1976), coincident with the final stages of cochlear cytodifferentiation (Kikuchi and Hilding 1965; Mikaelian and Ruben 1965; Shnerson et al. 1982). Consistent with that view, when hypothyroidism is induced in rats and mice after P10 or so-just around the time that evoked potentials are first observed in altricious rodents-ensuing peripheral auditory pathology is relatively minor. More severe anatomical abnormalities occur when hypothyroidism is initiated earlier in postnatal life or, especially, prior to the time that autonomous secretion of thyroxin occurs in developing fetuses, according to the work of Deol (1973) and Hébert et al. (1985b). Thus, the common view has been that a critical, thyroxin-dependent period exists in mice and rats that extends from just before birth to roughly the middle to end of the second postnatal week, approximately coincident with the first sign of sound-elicited cochlear activity.

The specific aims of the current study were to assess the capacity of prenatal exogenous $\mathrm{T}_{4}$ replacement to prevent auditory dysfunction, ascertained using the auditory brainstem response (ABR), and to determine the relative potency of $\mathrm{T}_{4}$ replacement during key postnatal developmental periods in the $T s h r^{\text {hyt }}$ homozygous mutant mouse.

\section{MATERIALS AND METHODS}

\section{Study design}

ABRs were recorded from hyt/hyt mice produced by male $h y t / h y t \times$ female $h y t / h y t$ breeding pairs. This breeding strategy produced $h y t / h y t_{(\mathrm{h})}$ offspring, according to the nomenclature of Sprenkle et al. (2001b), where the " $h$ " subscript represents the hypothyroid condition of the dam from which the pups were derived; when offspring were derived from euthyroid, heterozygous dams, they are designated with an "e" subscript. Experimental subjects were treated with $\mathrm{T}_{4}$ or saline placebo during specified prenatal and postnatal periods between conception (E0) and P28. Five separate groups were studied:

1. No $\mathrm{T}_{4}$-received placebo throughout the period of study;

2. $\mathrm{T}_{4}: \mathrm{P} 0-\mathrm{P} 28$ - received $\mathrm{T}_{4}$ during the postnatal period only (P0-P28);

3. $\mathrm{T}_{4}$ : $\mathrm{E} 0-\mathrm{E} 21$-received $\mathrm{T}_{4}$ during the prenatal period only; note that gestational period was not monitored for each litter and the E21 designation simply refers to the end of the prenatal period;
4. $\mathrm{T}_{4}: \mathrm{E} 0-\mathrm{P} 14$-received $\mathrm{T}_{4}$ throughout the prenatal period and during the first 14 postnatal days;

5. $\mathrm{T}_{4}$ : E0-P28-received $\mathrm{T}_{4}$ throughout the prenatal period and throughout the postnatal period of study.

Nine to 12 mice were included in each group and subjects were drawn from 20 litters. Creighton University's Animal Care and Use Committee approved the protocols employed in the care and use of animals used in this study.

\section{Animal husbandry}

Animals were bred and housed as described in Sprenkle et al. (2001a). Formulab Chow 5008 (Purina Mills, Inc., Richmond, IN, USA) was supplemented with thyroid powder prior to and between matings to enhance fertility. Supplementation was discontinued in female breeders at the time thyroxin pellets were implanted (see below). Both male and female progeny remained with the dam until the time of testing on P28.

\section{$\mathrm{T}_{4}$ replacement therapy}

Prenatal treatment of animals in utero was achieved by administering thyroxin $\left(\mathrm{T}_{4}\right)$ to female breeders according to a standard protocol that calls for treatment to begin on $\mathrm{P} 42$, two weeks prior to mating. Animals were implanted subdermally with 60-day controlled-release pellets containing either placebo or Lthyroxin (Innovative Research of America, Toledo, $\mathrm{OH}$, USA) using a standard trochar approach.

Postnatal $\mathrm{T}_{4}$ or saline placebo was administered according to the plan described in Sprenkle et al. (2001a). Variable doses of L-thyroxin designed to mimic normal age-matched thyroxin titers were injected subcutaneously on days $0-5$ (4 ng/g), 6-8 (5.8 ng/g), and 9-10 (9.1 ng/g) (Hébert et al. 1985b; Sprenkle et al. 2001b). Treatment was continued through either P14 or P28 according to a protocol requiring the administration of $14.0 \mathrm{ng} / \mathrm{g}$ on P11-P14 and alternate days between P16 and P28 (Dubois and Dussault 1977).

\section{Serum $\mathrm{T}_{4}$ determinations}

Serum $\mathrm{T}_{4}$ levels were determined in dams 3 and 50 days following pellet implantation and in experimental subjects on the day of testing, as described in Sprenkle et al. (2001a). Blood was collected from the tail vein and $5-\mu \mathrm{L}$ aliquots were assayed in duplicate by radioimmunoassay. The assay detection limit for $\mathrm{T}_{4}$ was 0.01 $\mu \mathrm{g} / \mathrm{dL}$. 


\section{Behavioral assessments}

Daily notations were made to identify gross physical changes (e.g., body weights and ages associated with eye-opening and pinna-unfolding) and behavioral differences (circling tendency, righting reflex, and posture) among the groups. Behavioral evaluations were made on P21 and P28 as described in Sprenkle et al. (2001a).

\section{ABR measurements}

ABRs were assessed on P28 [the procedures used are described in detail in Sprenkle et al. (2001a)]. Briefly, subjects were anesthetized using chloral hydrate $(480$ $\mathrm{mg} / \mathrm{kg} \mathrm{IP})$ and supplemented as needed $(120 \mathrm{mg} / \mathrm{kg}$ IP). ABRs were recorded using subdermal electrodes positioned at the vertex (active), mastoid region (reference), and over the neck musculature (ground). Differentially recorded signals were amplified $(100,000 \times)$, band-pass filtered $(0.03-10 \mathrm{kHz})$, and digitized at a $20-\mathrm{kHz}$ sampling rate over a $20-\mathrm{ms}$ epoch that included a 5-ms baseline recorded prior to stimulus delivery. Each average consisted of 500 trials.

Digitally synthesized tone bursts $(3 \mathrm{~ms}$ in duration with 1-ms on/off ramps) and clicks (60 $\mu$ s in duration) were alternated in polarity and delivered at a rate of $5 / \mathrm{s}$ under free-field conditions via a high-impedance piezoelectric tweeter positioned $10 \mathrm{~cm}$ above the vertex. Stimulus levels (in dB SPL) are referenced to 20 $\mu \mathrm{Pa}$. Thresholds were determined for clicks and for tone bursts at 20, 16, 8, 4, and $2 \mathrm{kHz}$. Response level series were acquired using both clicks and tone bursts (20 and $8 \mathrm{kHz}$ ) starting below threshold and extending to $90 \mathrm{~dB}$ SPL in 5-dB steps. Two responses were acquired at each level.

\section{Data analysis}

Analysis of variance (ANOVA) was used to evaluate differences in body weights and ages of eye-opening and pinna-raising among the experimental groups. Tukey tests were used for multiple comparisons. ABR thresholds, wave latencies, interpeak intervals, and amplitudes were measured as in Sprenkle et al. (2001a). Nonparametric statistics (Kruskal-Wallis test) were used for intergroup comparisons and differences were considered significant at $p<0.01$, unless, otherwise stated.

\section{RESULTS}

\section{Somatic and behavioral characteristics}

Thyroxin serum levels in hyt/hyt dams implanted with controlled-release $\mathrm{T}_{4}$ pellets were significantly $(p<$

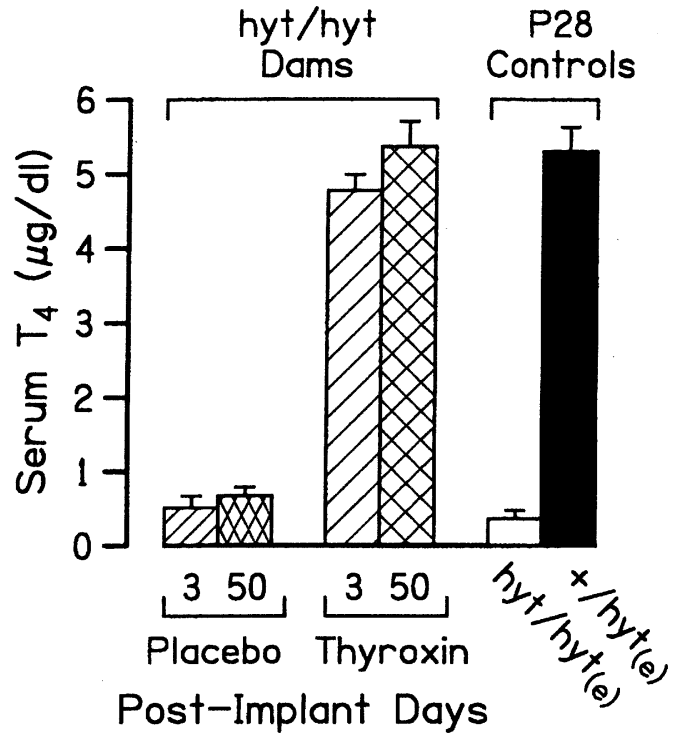

FIG. 1. Serum $T_{4}$ levels in Tshr mice. Titers of serum $T_{4}$ in hyt/hyt dams were measured 3 and 50 days following placebo (saline) or thyroxin pellet implantation and are compared with levels measured in 28-day-old hyt/hyt $(\mathrm{e})$ and $+/ h t_{(\mathrm{e})}$ mice derived from euthyroid, heterozygous dams (from Sprenkle et al. 2001b). Values represent means and standard errors.

$0.001)$ higher $(5.07 \pm 0.17 \mu \mathrm{g} / \mathrm{dL}, n=12)$ than in placebo-implanted dams $(0.59 \pm 0.07 \mu / \mathrm{dL}, n=8)$ at both 3 and 50 days following implantation (Fig. 1). Thus, all $\mathrm{T}_{4}$-treated dams were euthyroid throughout the period of pregnancy according to the commonly accepted criterion of $>4.0 \mu \mathrm{g}$ of $\mathrm{T}_{4} / \mathrm{dL}$ of serum (Adams et al. 1989). Moreover, as shown in Figure 1, $\mathrm{T}_{4}$ titers in placebo- and thyroxin-treated dams were comparable to values measured in untreated hypothyroid $\left(h y t / h t_{(\mathrm{e})}\right)$ and euthyroid $\left(+/ h_{y} t_{(\mathrm{e})}\right)$ mice derived from euthyroid, heterozygous dams, respectively (Sprenkle et al. 2001b). These results confirm that all experimental groups treated with thyroxin prenatally (i.e., the $\mathrm{T}_{4}$ : E0-E21, $\mathrm{T}_{4}$ : E0-P14, and $\mathrm{T}_{4}$ : E0-P28 groups) were exposed to significantly higher levels of $\mathrm{T}_{4}$ during prenatal life than groups born to untreated dams that were homozygous for the hyt allele (i.e., the No $\mathrm{T}_{4}$ and $\mathrm{T}_{4}$ : $\mathrm{P} 0-\mathrm{P} 28$ groups).

Serum thyroxin titers for hyt/hyt pups that were treated throughout postnatal development (circles) are compared with untreated pups (squares) in Figure 2. Note that the concentrations of $\mathrm{T}_{4}$ in animals receiving replacement therapy mimic those of age-matched heterozygote controls (derived from euthyroid dams), whereas those receiving placebo mimic those of hyt/hyt pups derived from either heterozygous or homozygous mutant dams (Sprenkle et al. 2001b). Serum $\mathrm{T}_{4}$ titers decreased rapidly when thyroxin treatment was discontinued on P10 and P14, although elevated levels were observed for 2-4 days following the last treatment.

Both groups actively receiving $\mathrm{T}_{4}$ on $\mathrm{P} 28\left(\mathrm{~T}_{4}\right.$ : $\mathrm{P} 0-$ 


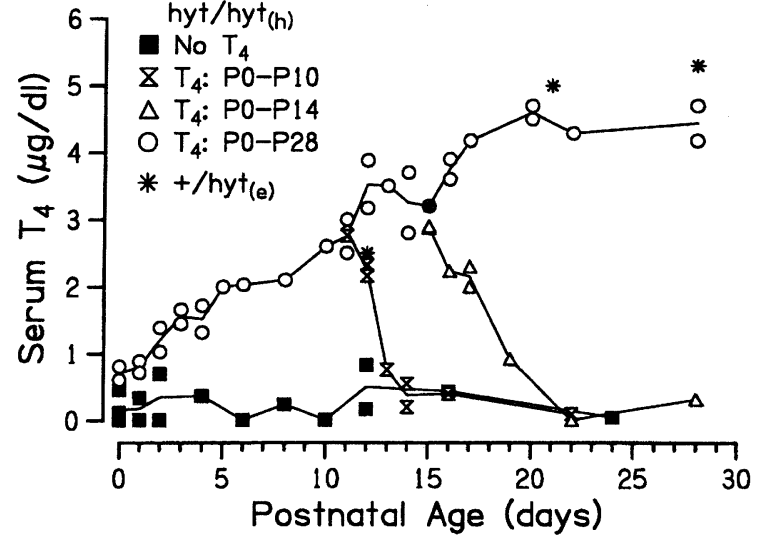

FIG. 2. Developmental changes in serum $\mathrm{T}_{4}$ levels in placebo- and thyroxin-treated mice. The relationship between serum $\mathrm{T}_{4}$ titers and age is shown for individual hyt/hyt $t_{(h)}$ mice that were not treated with thyroxin (placebo controls; open squares), and those that were treated with $\mathrm{T}_{4}$ at the indicated age ranges (see symbol key). Lines represent averages for each group. Data used for this figure were obtained from a separate set of animals than that used for ABR recordings (Sprenkle 1997). Asterisks represent serum titers for $+/ h y t_{(\mathrm{e})}$ mice at P12, P15, P21, and P28 from Sprenkle et al. (2001b).

P28 and $\mathrm{T}_{4}$ : E0-P28) were euthyroid based on assay findings at the time of $\mathrm{ABR}$ testing and $\mathrm{T}_{4}$ titers were essentially the same (Table 1 ). Likewise, $\mathrm{T}_{4}$ levels were unambiguously in the hypothyroid range at the time of testing when $\mathrm{T}_{4}$ treatment was stopped on P14 or earlier.

All mice born to $\mathrm{T}_{4}$-treated dams had higher body weights $(p<0.001)$ than mice born to placebo-treated dams by P28, and mice treated throughout the study period $\left(\mathrm{T}_{4}: \mathrm{E} 0-\mathrm{P} 28\right)$ weighed significantly more than animals whose treatment ended on P14 ( $\mathrm{T}_{4}$ : E0-P14) (Table 1). Body weight differences between animals treated with $\mathrm{T}_{4}$ prenatally and those that were not were observed at all ages studied, and differences between the groups increased with age (Sprenkle 1997). Pups treated after birth but not prenatally $\left(\mathrm{T}_{4}\right.$ : $\left.\mathrm{P} 0-\mathrm{P} 28\right)$ grew at the same rate as untreated animals $\left(\mathrm{No} \mathrm{T}_{4}\right)$, underscoring the importance of prenatal thyroxin and the limited developmental advantage gained by exposing homozygotes to thyroxin during postnatal life alone.

Consistent with body weight growth findings, $\mathrm{T}_{4}$ treatment affected the development of other notable somatic features like eye-opening and pinna-raising. Both of these indices of maturation occurred earlier $(p<0.001)$ in individuals treated through $\mathrm{P} 14$ or $\mathrm{P} 28$, relative to other groups studied in this investigation (Table 1). In addition, circling behavior was observed in a small percentage of animals that were not treated prenatally (i.e., $22 \%$ of the $\mathrm{No}_{4}$ group and $11 \%$ of the $\mathrm{T}_{4}$ : $\mathrm{P} 0-\mathrm{P} 28$ group) and a small percentage of the group that was treated only prenatally $\left(10 \%\right.$ of the $\mathrm{T}_{4}$ : E0-E21 group). Circling behavior was not observed in the 2 groups that were treated prenatally and postnatally through P14 or P28 ( $\mathrm{T}_{4}$ : E0-P14 and $\mathrm{T}_{4}$ : E0-P28). Out of the entire study, only one animal responded abnormally to the tail-hanging test, and this individual also displayed circling behavior. Interestingly, this subject was treated for the full postnatal regimen but not prenatally.

\section{General findings}

As noted in Sprenkle et al. (2001b), hyt/hyt mice that are born to hypothyroid dams fail to develop normal auditory function. Consistent with that finding, all untreated animals studied here were remarkably abnormal on the day of testing (i.e., P28). This is clear when responses produced by high-level stimuli are compared for individuals that were hypothyroid (i.e., $\mathrm{No}_{4}$ ) and those that were euthyroid (i.e., $\mathrm{T}_{4}$ :

\begin{tabular}{|c|c|c|c|c|c|}
\hline \multicolumn{6}{|c|}{ Somatic and behavioral characteristics } \\
\hline & $\mathrm{No} T_{4}$ & $T_{4}: P O-P 28$ & $T_{4}: E O-E 21$ & $T_{4}: E O-P 14$ & $T_{4}: E O-P 28$ \\
\hline Serum $\mathrm{T}_{4}{ }^{1}(\mu \mathrm{g} / \mathrm{dL})$ & $0.34 \pm 0.10$ & $4.82 \pm 0.34^{\mathrm{a}}$ & $0.38 \pm 0.09$ & $0.32 \pm 0.08$ & $5.13 \pm 0.22^{a}$ \\
\hline Birth weight ${ }^{2}(\mathrm{~g})$ & $1.23 \pm 0.11^{b}$ & $1.28 \pm 0.19^{b}$ & $1.49 \pm 0.12$ & $1.41 \pm 0.14$ & $1.44 \pm 0.15$ \\
\hline Weight at $\mathrm{P} 28^{2}(\mathrm{~g})$ & $9.2 \pm 0.5^{c}$ & $9.9 \pm 0.4^{c}$ & $11.7 \pm 1.6^{\mathrm{d}}$ & $13.0 \pm 0.8^{d}$ & $16.5 \pm 0.6^{\mathrm{d}}$ \\
\hline Eye-opening age ${ }^{3}$ & $17.1 \pm 1.2^{\mathrm{e}}$ & $17.2 \pm 0.8^{\mathrm{e}}$ & $16.5 \pm 0.8^{\mathrm{e}}$ & $15.2 \pm 1.1$ & $14.2 \pm 1.1$ \\
\hline Pinna-raising age ${ }^{3}$ & $20.0 \pm 1.1^{\mathrm{e}}$ & $20.0 \pm 1.4^{\mathrm{e}}$ & $19.5 \pm 1.4^{\mathrm{e}}$ & $17.4 \pm 1.2$ & $16.4 \pm 1.4$ \\
\hline Tail-hanging test & $0 / 9$ & $1 / 9$ & $0 / 10$ & $0 / 10$ & $0 / 12$ \\
\hline Circling behavior & $2 / 9$ & $1 / 9$ & $1 / 10$ & $0 / 10$ & $0 / 12$ \\
\hline
\end{tabular}

Sample size for each measurement is indicated as the total number of animals tested for circling behavior under the appropriate column.

${ }^{1}$ Mean \pm SEM.

${ }^{2}$ Mean $\pm \mathrm{SD}$.

${ }^{3}$ Mean $\pm \mathrm{SD}$, in postnatal days.

${ }^{a} p<0.001$ vs. the following groups: $\mathrm{No} \mathrm{T}_{4}, \mathrm{~T}_{4}: \mathrm{E} 0-\mathrm{E} 21$, and $\mathrm{T}_{4}: \mathrm{E} 0-\mathrm{P} 14$

${ }^{\mathrm{b}} p<0.01$ vs. $\mathrm{T}_{4}: \mathrm{E} 0-\mathrm{E} 21$.

${ }^{c} p<0.001$ vs. $\mathrm{T}_{4}: \mathrm{E} 0-\mathrm{E} 21, \mathrm{~T}_{4}: \mathrm{E} 0-\mathrm{P} 14$, and $\mathrm{T}_{4}: \mathrm{E} 0-\mathrm{P} 28$.

${ }^{d} p<0.001$ vs. all other groups.

${ }^{\mathrm{e}} p<0.001$ vs. $\mathrm{T}_{4}$ : E0-P14 and $\mathrm{T}_{4}$ : E0-P28. 


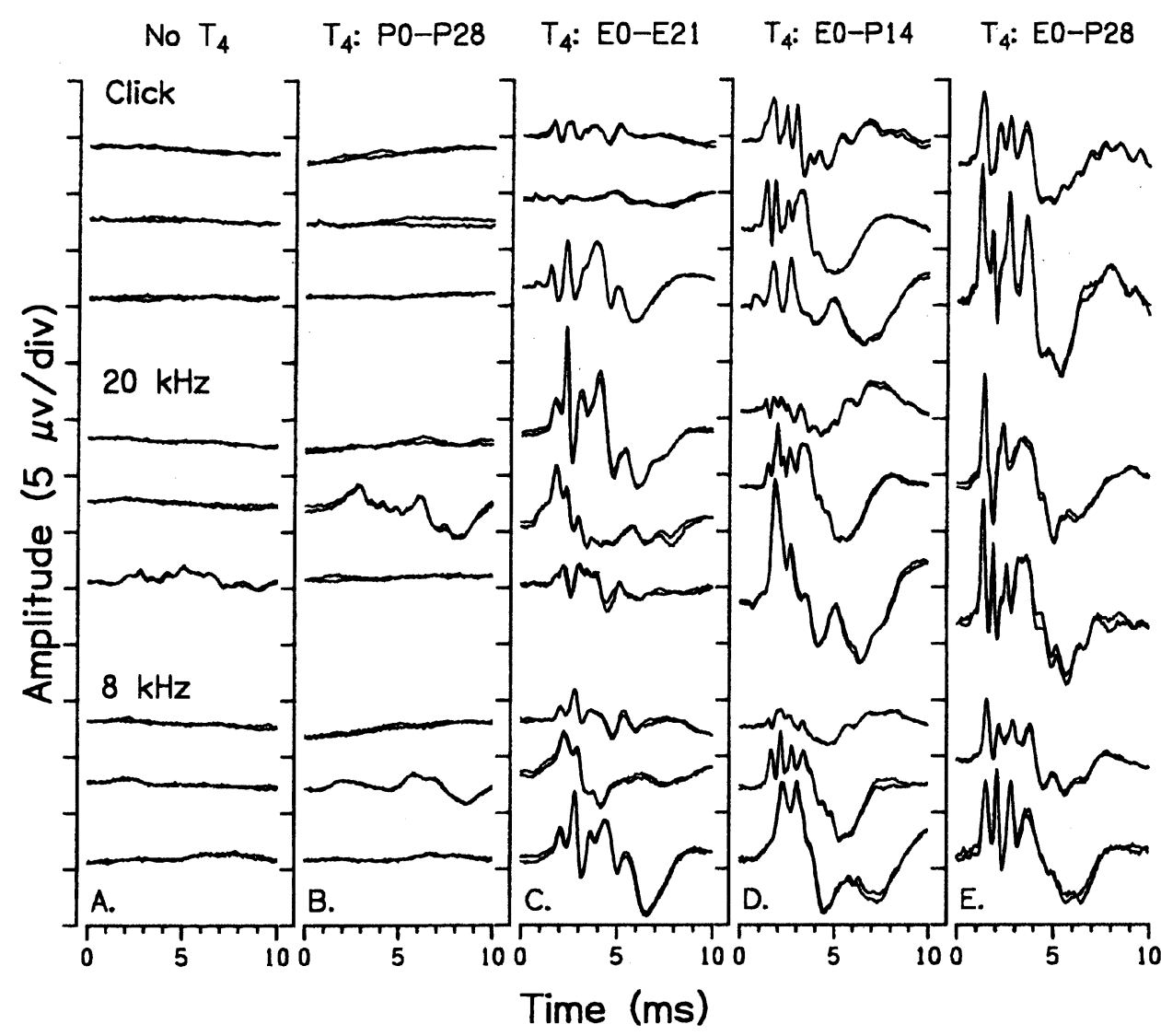

FIG. 3. Representative examples of $A B R$ waveforms. ABR records are shown for individual mice within each of the five experimental groups $(\mathbf{A}-\mathbf{E})$ in response to clicks (top rows), $20 \mathrm{kHz}$ (middle rows), and $8 \mathrm{kHz}$ (bottom rows). For $\mathbf{A}-\mathbf{D}$, $\mathrm{ABR}$ waveforms of 3 mice are shown, and in $\mathbf{E}$, waveforms of 2 mice are shown. Stimuli were presented at $90 \mathrm{~dB}$ SPL. Two replicates are shown overlapping for each individual.
E0-P28) throughout the study period, as shown in Figures $3 \mathrm{~A}$ and E. While approximately $20 \%$ of the untreated animals responded to $90 \mathrm{~dB}$ SPL tone bursts at $20 \mathrm{kHz}$, even fewer responded to $8 \mathrm{kHz}$, and clicks were completely ineffective at that level.

When $\mathrm{T}_{4}$ treatment was limited to the postnatal period $\left(\mathrm{T}_{4}: \mathrm{P} 0-\mathrm{P} 28\right)$, individuals were slightly more responsive than their untreated counterparts, while the difference between responses observed in pups treated only during the postnatal period $\left(\mathrm{T}_{4}: \mathrm{P} 0-\mathrm{P} 28\right)$ and those treated throughout the pre- and postnatal period were obvious (Figs. 3B and E). Responses were highly variable among mice whose treatment ended at birth $\left(\mathrm{T}_{4}\right.$ : E0-E21), but all four waves were easily identified in most animals (Fig. 3C).

The influence of thyroxin treatment after P14 was also substantial, as indicated in the gross comparison of ABR waveforms associated with $\mathrm{T}_{4}$ : $\mathrm{E} 0-\mathrm{P} 14$ and $\mathrm{T}_{4}$ : E0-P28 groups (Figs. 3D and E). Although all animals responded at $90 \mathrm{~dB}$ SPL for the three stimulus conditions shown, responses recorded from individuals that were euthyroid throughout the study period were more robust and showed signs of greater maturity, as in reduced intragroup variability, shorter latencies, and larger amplitudes. In general, ABRs elicited from this group were completely normal, with all four major peaks occurring within the first $5 \mathrm{~ms}$ of the response. As with ABRs from other mammals, wave splitting was relatively common at high stimulus levels for waves II, III, and IV. In particular, wave II often split into two peaks at levels $\geq 80 \mathrm{~dB}$ SPL and the appearance of a trailing shoulder on wave IV was common. Adjacent peaks occasionally merged, particularly between waves II and III, and this phenomenon occurred more frequently in response to tone bursts than in response to clicks. Overall, response waveforms appeared to exhibit normal level-dependent alterations, including decreased amplitudes and increased latencies as stimulus level was decreased (Fig. 4).

\section{Incidence of response}

The overall responsiveness of experimental groups studied as a part of this investigation was determined by plotting the percentage of animals within each group that responded to a specific stimulus as a function of level (Fig. 5). This analytical approach allows the straightforward comparison of responsiveness among the study groups and, consequently, the determination of the relative efficacy of thyroxin treatment during specified developmental stages. In such an analysis, a smooth, rapidly growing function that 

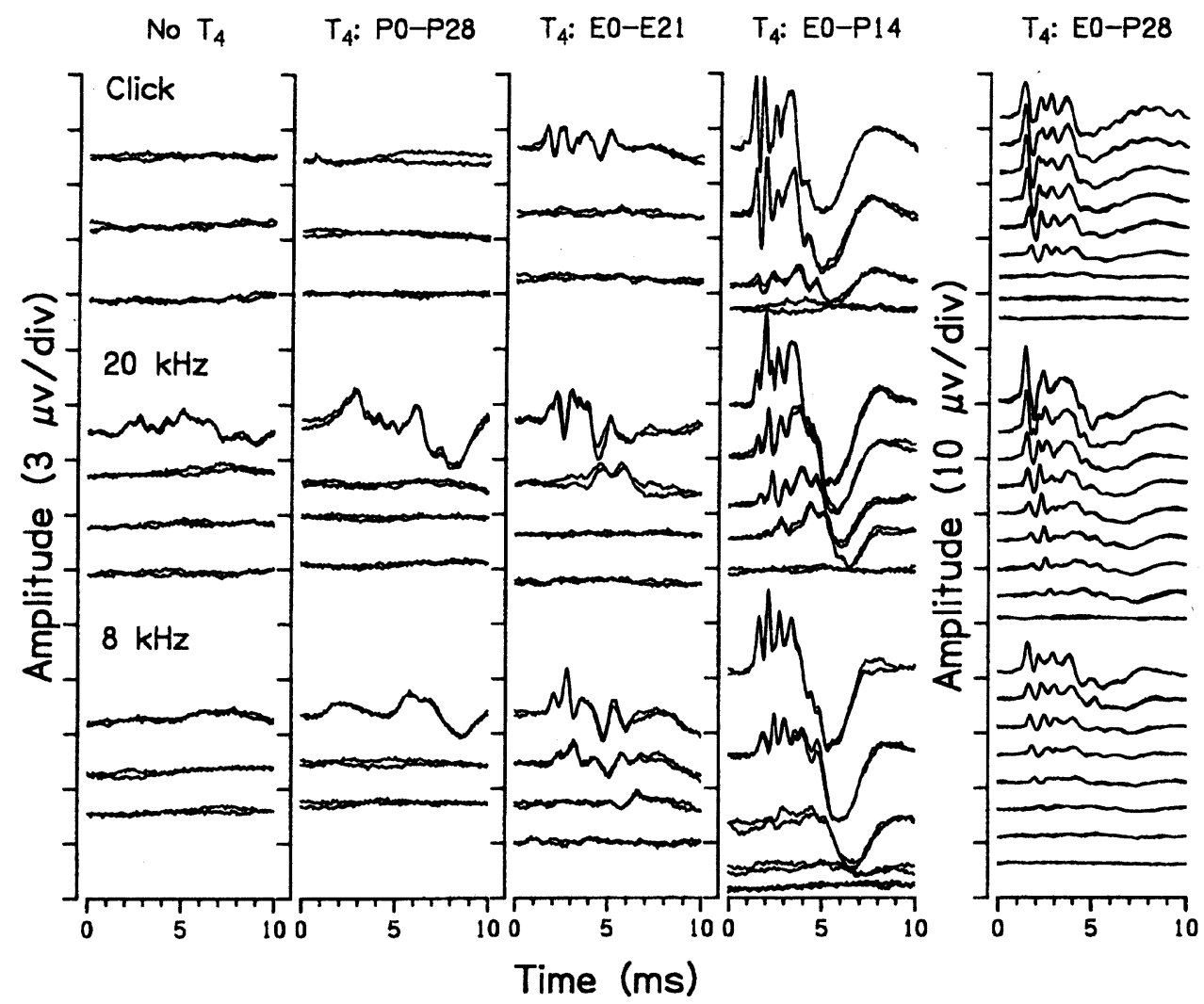

FIG. 4. Level-dependent changes in $A B R$ waveforms. $A B R$ records from each experimental group (columns) are plotted in response to a range of levels for clicks (top rows), $20 \mathrm{kHz}$ (middle rows), and $8 \mathrm{kHz}$ (bottom rows). Each set of waveforms represents responses to stimuli starting at $90 \mathrm{~dB}$ SPL (upper trace of set) and decreasing in 10-dB steps (successively lower traces). Two replicates are shown overlapping at each level. Note the change in amplitude scale for the fully treated group $\left(\mathrm{T}_{4}\right.$ : $\left.\mathrm{E} 0-\mathrm{P} 28\right)$ in the rightmost column.

reaches $100 \%$ at a relatively low stimulus level is characteristic of a highly responsive group whose thresholds are distributed normally over a narrow range of values. Response incidence curves with those characteristics were observed among animals that were treated with thyroxin throughout the full range of the study period (i.e., the $\mathrm{T}_{4}$ : E0-P28 category) (Fig. 5 , diamonds). A clearly detectable portion $(\sim 10 \%)$ of that population responded to stimulus levels in the range of 10-15 dB SPL for frequencies that lie in the most sensitive part of the heterozygote's audiometric range (20 and $16 \mathrm{kHz}$ ), whereas clicks and $8-\mathrm{kHz}$ tones had to be as high as 20-30 dB SPL to elicit responses in a small percentage of the population. For lower-frequency stimuli falling outside the most sensitive band of the audiometric range, $\sim 10 \%$ of the group responded to $40-45 \mathrm{~dB}$ SPL for $4-\mathrm{kHz}$ tones and 65-70 dB SPL for $2 \mathrm{kHz}$.

The only stimulus conditions producing responses in the untreated group $\left(\mathrm{No} \mathrm{T}_{4}\right)$ were very high-level tone bursts. Threshold responses always exceeded 80 $\mathrm{dB}$ SPL and the percentage of untreated animals that responded to any acoustic stimulus never exceeded $50 \%$.

Response incidence curves representing intermediate treatment groups, designated $\mathrm{T}_{4}$ : $\mathrm{E} 0-\mathrm{P} 14, \mathrm{~T}_{4}$ : $\mathrm{E} 0-\mathrm{E} 21$, and $\mathrm{T}_{4}$ : $\mathrm{P} 0-\mathrm{P} 28$, indicated that the efficacy of thyroxin treatment was graded and dependent on developmental stage. When thyroxin was administered throughout the combined prenatal period and the first 14 postnatal days, the overall responsiveness of the group was diminished relative to those treated throughout the entire study period as indicated by the rightward shift of sensitivity curves for all stimulus conditions. Unlike the smooth growth curves representing the $\mathrm{T}_{4}$ : E0-P28 group, growth curves were irregular, suggesting that the distribution of thresholds within those populations was broad. The level required to produce responses among the most sensitive members of this group was slightly higher $(\sim 10$ $\mathrm{dB}$ for most conditions) than that observed in the group that was treated throughout the study period. However, as indicated by the extended dynamic range of representative population functions, many if not most individuals were notably less sensitive than the most sensitive representatives of the group, frequently by as much as $30 \mathrm{~dB}$.

Animals treated during the prenatal period alone (the $\mathrm{T}_{4}$ : E0-E21 group) were more responsive than either untreated animals or individuals treated during the full postnatal period, but not prenatally (the $\mathrm{T}_{4}$ : $\mathrm{P} 0-\mathrm{P} 28$ group). The most sensitive animals responded in the range of $60-80 \mathrm{~dB}$ SPL above 4 $\mathrm{kHz}$ and incidence curves were generally smooth and steep, suggesting that thresholds are tightly and normally distributed among individuals in this group. 


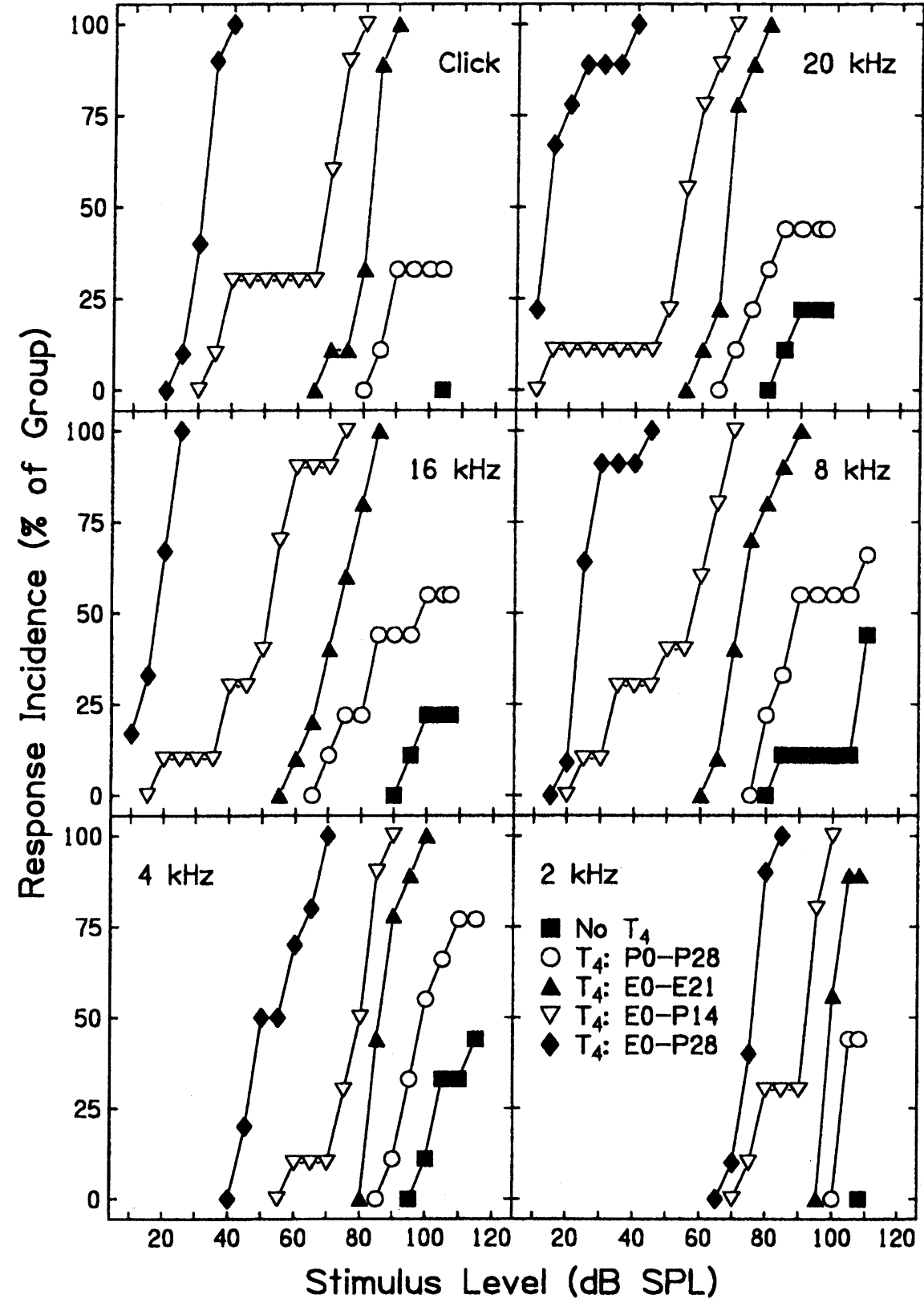

FIG. 5. Effects of thyroxin treatment on response incidence-stimulus level curves. The percentage of mice within each study group that responded to clicks and tone bursts is plotted as a function of stimulus level. The symbol key for all panels is located in the bottom-right panel. Nine to 12 mice were tested in each group.
This finding supports the view that prenatal exposure to $\mathrm{T}_{4}$ is relatively more important to inner-ear development than postnatal exposure alone.

\section{ABR thresholds}

As expected based on findings from the analysis of response incidence curves, when detectable, the thresholds of untreated $\left(\mathrm{No} \mathrm{T}_{4}\right)$ mice were very near the output limits of the sound delivery system (Fig. 6). Although somewhat more sensitive on average, thresholds of animals treated during the full postnatal period but not prenatally (the $\mathrm{T}_{4}$ : $\mathrm{P} 0-\mathrm{P} 28$ group) were also very high, in the neighborhood of 90-100 dB SPL. While mice that were treated in the prenatal period alone $\left(\mathrm{T}_{4}: \mathrm{E} 0-\mathrm{E} 21\right)$ were more sensitive to acoustic stimulation than those treated in the postnatal period alone, the enhanced sensitivity did not achieve statistical significance relative to the untreated group for any stimulus condition. However, threshold improvement became significant relative to untreated mice $\left(\mathrm{No}_{4}\right)$ when $\mathrm{T}_{4}$ treatment was continued through at least $\mathrm{P} 14\left(\mathrm{~T}_{4}: \mathrm{E} 0-\mathrm{P} 14\right)$, and fully treated mice ( $\mathrm{T}_{4}$ : E0-P28), who were comparable to individuals in the hyt $/+_{(\text {e) }}$ category of Sprenkle et al. (2001b), had the lowest thresholds of all five groups at all frequencies tested. These improvements were significant with respect to all groups except those who received $\mathrm{T}_{4}$ through P14.

As shown in the form of response incidence curves 


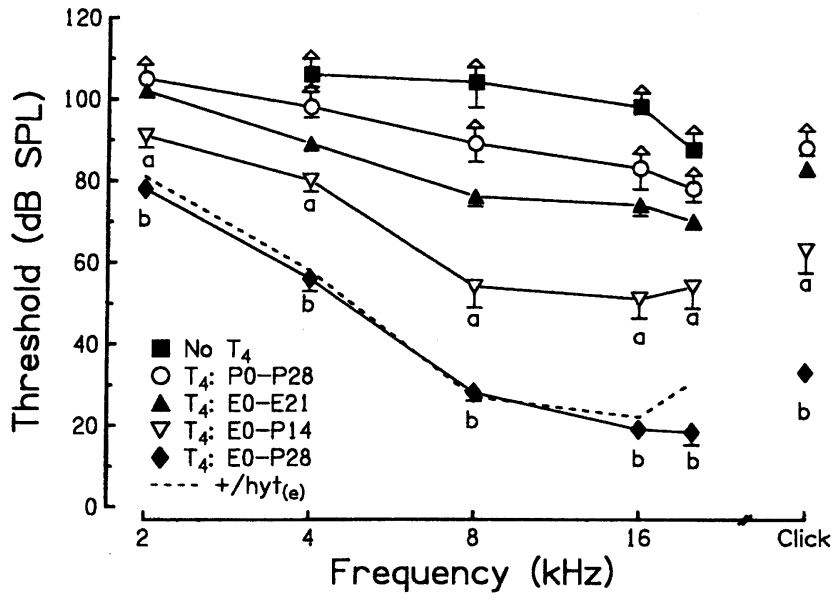

FIG. 6. Effects of thyroxin treatment on frequency-threshold curves. Average ABR thresholds of each experimental group (see symbol key) are plotted as a function of stimulus frequency. Thresholds for click stimuli are also shown. Upward-pointing arrows denote instances in which one or more mice exhibited no measurable response at the highest stimulus level used. Error bars represent the SEM of 9-12 mice tested per group. Dashed line represents thresholds of 28-dayold heterozygotes derived from euthyroid dams $\left(+/ h y t_{(\mathrm{e})}\right)$ reported in Sprenkle (2001b). Letter designations next to symbols represent statistically significant differences $(p<0.01)$ between the indicated group and the following groups: "a," versus No $T_{4}$ and versus $T_{4}$ : P0-P28; "b," versus $\mathrm{No} \mathrm{T}_{4}$, versus $\mathrm{T}_{4}$ : P0-P28, and versus $\mathrm{T}_{4}$ : E0-E21.

previously, the discovery that prenatal thyroxin has a nonlinear cumulative influence on subsequent development is clear when threshold-frequency plots for animals treated throughout the postnatal period alone $\left(\mathrm{T}_{4}: \mathrm{P} 0-\mathrm{P} 28\right)$ are compared with threshold-frequency plots representing individuals that were treated during the prenatal period only $\left(\mathrm{T}_{4}: \mathrm{E} 0-\mathrm{E} 21\right)$. It is clear that postnatal exposure to thyroxin is essentially ineffective when an individual's prenatal history is one of hypothyroidism.

\section{Input-output relationships}

Input-output (I/O) functions were analyzed with respect to absolute latencies, interpeak intervals, and amplitudes for all five groups studied. Because of the high thresholds that are characteristic of groups that did not receive prenatal $\mathrm{T}_{4}$, responses from $\mathrm{No} \mathrm{T}_{4}$ and $\mathrm{T}_{4}$ : $\mathrm{P} 0-\mathrm{P} 28$ groups were often unobtainable, or, at best, individuals from these groups responded to only the highest stimulus levels studied. For this reason, analysis of input-output characteristics was limited to the three groups that were treated during the prenatal period. When available, however, mean responses of the No $\mathrm{T}_{4}$ and $\mathrm{T}_{4}: \mathrm{P} 0-\mathrm{P} 28$ groups are shown for comparison with other groups (i.e., Figs. 8, 10, 11, and 13). As shown in relevant figures, response latencies were greatly prolonged and amplitudes greatly reduced among individuals that were not exposed to prenatal $\mathrm{T}_{4}$ relative to individuals treated during prenatal life.
ABR wave latencies. The overall form of latencyintensity curves representing the groups studied here was consistent with the well-established principle that response latency decreases as stimulus level increases (Fig. 7). Response variability was relatively low and input-output $(\mathrm{I} / \mathrm{O})$ curves were tightly distributed when animals were treated with thyroxin over the entire study period (i.e., the $\mathrm{T}_{4}$ : E0-P28 condition). $\mathrm{I} / \mathrm{O}$ curve slopes and dynamic ranges were similar among members of this group, regardless of wave number (Fig. 7, right column).

On the other hand, response latencies were widely distributed and notably prolonged among a large portion of individuals who received thyroxin during the prenatal period only ( $\mathrm{T}_{4}$ : E0-E21 group) (Fig. 7, leftmost column). Dynamic range was notably small among representatives of this group and the slopes of individual curves were similar. When latency-intensity curves from animals that had been treated throughout prenatal life plus the first 14 postnatal days $\left(\mathrm{T}_{4}\right.$ : E0P14) were compared with this group, a subpopulation responded with normal wave I latencies to high-level stimulation (i.e., $>60 \mathrm{~dB}$ SPL), although response latencies from the overall population were highly variable (Fig. 7, middle column), as in the case of the $\mathrm{T}_{4}$ : E0-E21 group.

The cumulative advantage of administering $\mathrm{T}_{4}$ throughout development, and the essential nature of prenatal exposure to the hormone for normal auditory development, is graphically depicted in the form of average latency-level curves for responses to clicks and tone bursts of 20 and $8 \mathrm{kHz}$ in Figure 8. When thyroxin was withheld during the prenatal period (squares and circles), although mean latencies generally decreased with level, response latencies were greatly prolonged regardless of condition or wave number. When considering those experimental groups that were exposed to prenatal thyroxin (triangles and diamonds), mean latencies also decreased with level, although latencies rarely achieved normal values when thyroxin was discontinued on or before P14. It is interesting that the extent of recovery, here defined in relation to normal age-matched values, was dependent on the degree of thyroxin exposure (see below). Notably, prenatal exposure to thyroxin alone (upward-pointing triangles) produced more recovery of function than thyroxin administered throughout the entire first postnatal month alone (circles). The occasional irregularity observed in average latencylevel curves for the $\mathrm{T}_{4}$ : E0-P14 group (downward-pointing triangles in Fig. 8) is indicative of the bimodal character of latency-level functions comprising this group.

Although more evident in some cases than others, latency was inversely related to the duration of thyroxin exposure (Fig. 9, upper panels), as was the steepness 


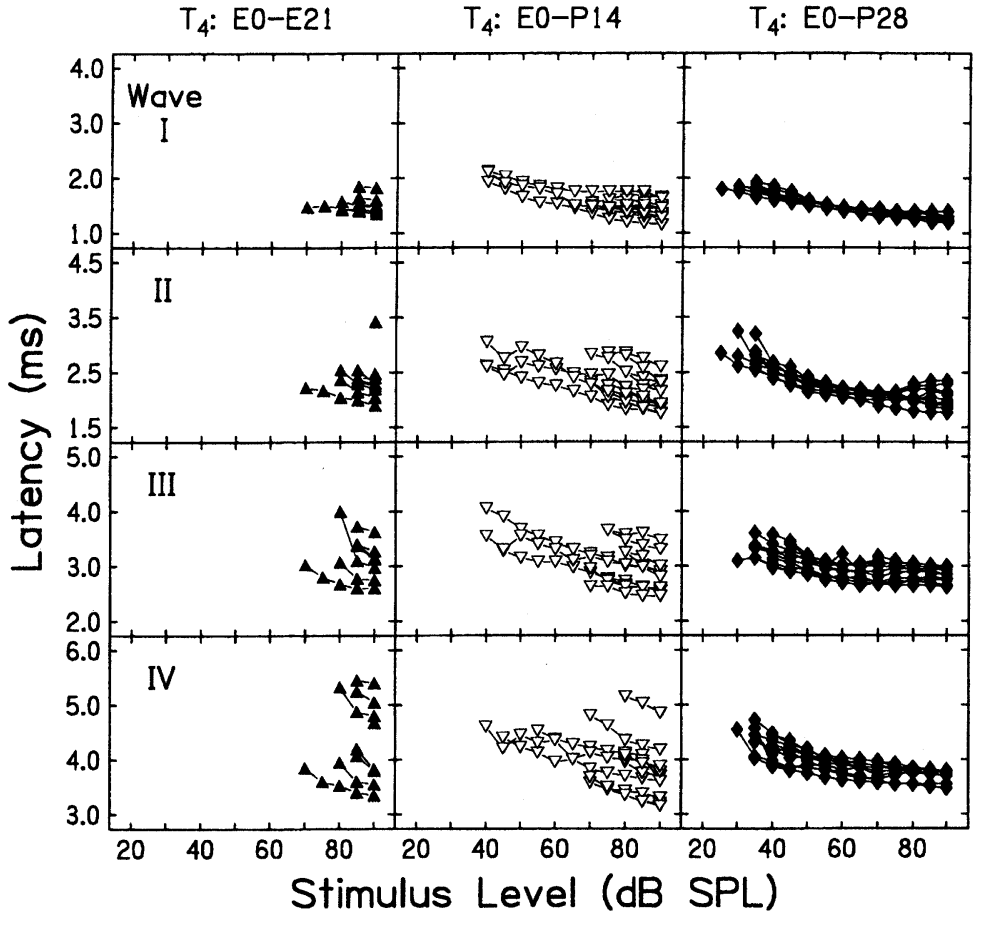

FIG. 7. Latency-level functions of thyroxin-treated mice. Click-evoked latencies for ABR waves I-IV (top to bottom rows) are plotted as a function of stimulus level for three of the experimental groups (columns). Each curve represents the responses of one individual.

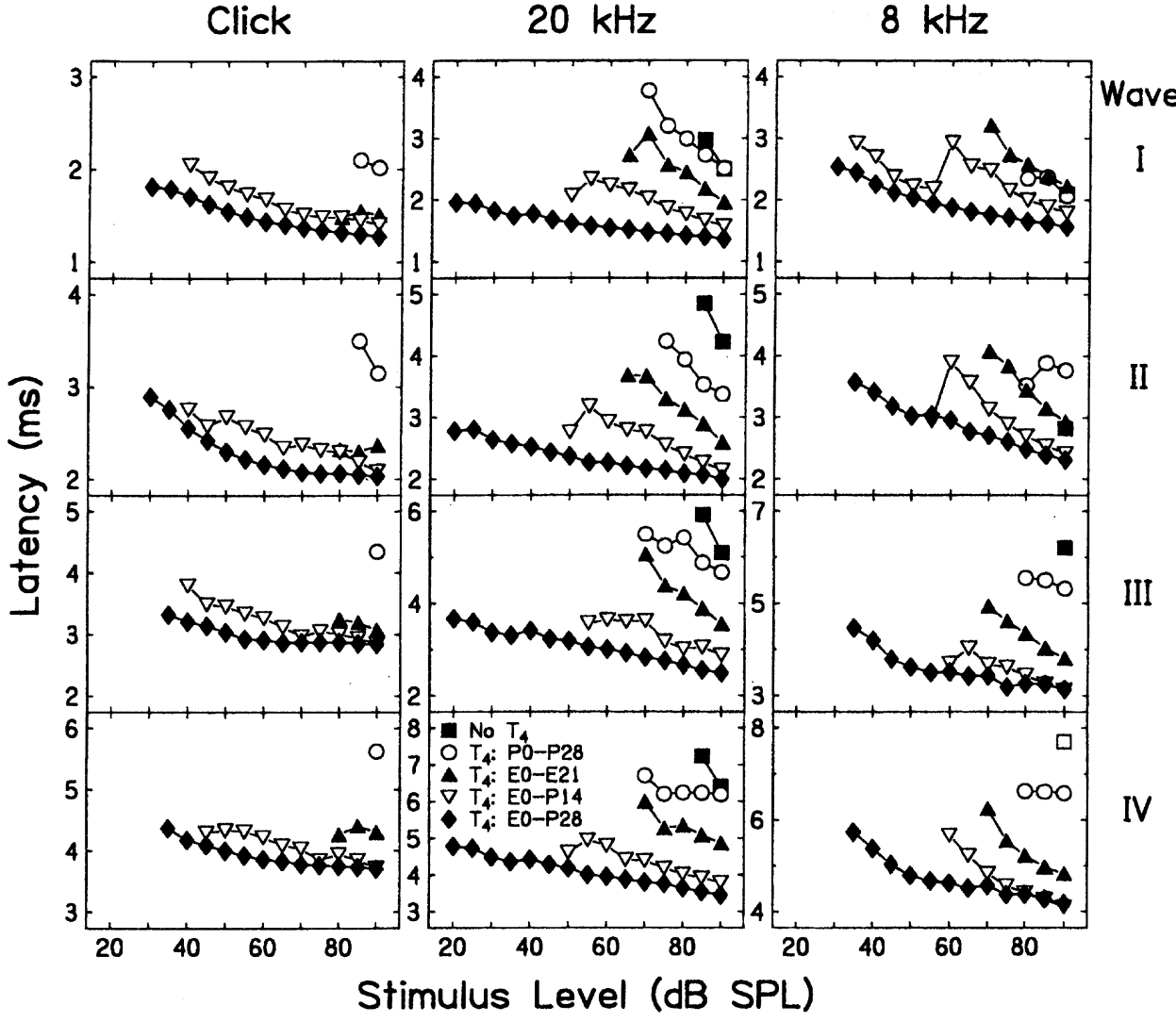

FIG. 8. Effects of thyroxin treatment on latency-level functions. Mean latencies of ABR waves I-IV (top to bottom rows) for each responsive group are plotted as a function of stimulus level for clicks (left column), $20 \mathrm{kHz}$ (middle column), and $8 \mathrm{kHz}$ (right column). Symbol key for all panels is shown in the lower-middle panel. Means are shown for only two or more values at a given stimulus condition except for the $\mathrm{NoT}_{4}$ and $\mathrm{T}_{4}$ : $\mathrm{PO}-\mathrm{P} 28$ groups for which means from all responses are included. of latency-level curve slopes among animals treated with thyroxin during the prenatal period (Fig. 9, lower panels), regardless of stimulus conditions. Latency differences between those homozygotes that were treated with $\mathrm{T}_{4}$ during prenatal life only $\left(\mathrm{T}_{4}\right.$ : E0-E21) and those treated throughout the period of study $\left(\mathrm{T}_{4}: \mathrm{E} 0\right.$ P28) were significant in the case of wave I for clicks and tone bursts presented at $90 \mathrm{~dB}$ SPL and, although 


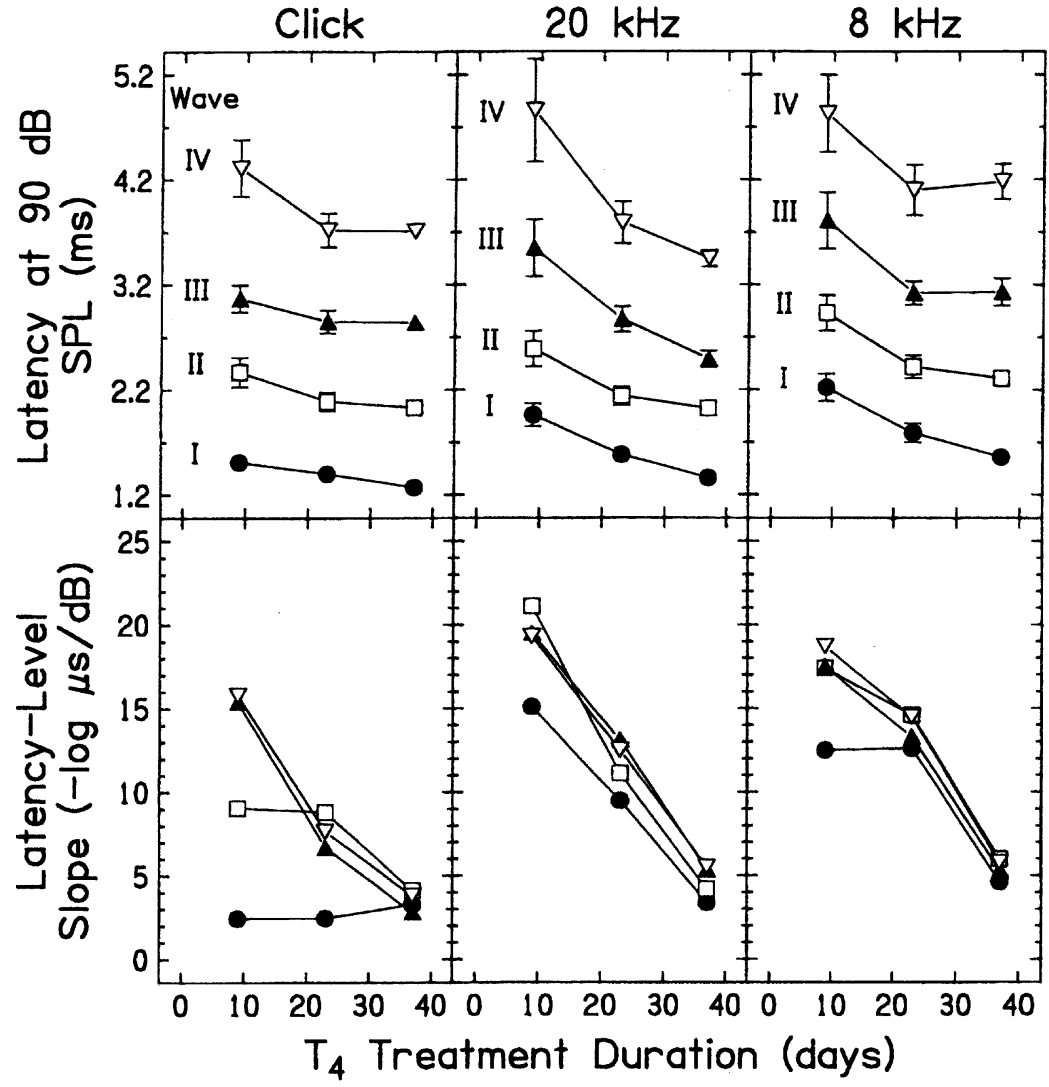

FIG. 9. Influence of thyroxin treatment duration on latencies and slopes of latency-level curves. Mean latencies at $90 \mathrm{~dB}$ SPL (top row) and mean slopes of latency-level curves (bottom row) are plotted for ABR waves I through IV in response to clicks (left column), $20 \mathrm{kHz}$ (middle column), and $8 \mathrm{kHz}$ (right column), as a function of thyroxin $\left(\mathrm{T}_{4}\right)$ treatment duration. Values plotted at 9 days represent animals that were treated prenatally only $\left(\mathrm{T}_{4}\right.$ : EO-E21); 9 days is based on the age range from the time that thyroid hormone receptors are first detected in the inner ear (Bradley et al. 1994) to the time of birth (21 days gestation). Values at 23 days represent treatment during the 9 days in utero to $\mathrm{P} 14\left(\mathrm{~T}_{4}\right.$ : E0-P14 group), and the values at 37 days represent an additional 14 days of treatment ( $\mathrm{T}_{4}$ : E0-P28 group). Slopes of latency-level curves were computed by normalizing latencies to the value measured at $90 \mathrm{~dB}$ SPL (subtracting that value and adding 1), converting to logarithmic values, and then performing a least-squares linear regression to the data. not achieving significance, other waves followed the same pattern. There were statistically significant differences $(p<0.01)$ in slopes of latency-level curves between animals treated for 9 days $\left(\mathrm{T}_{4}\right.$ : E0-E21 group) and those treated throughout the study period $\left(\mathrm{T}_{4}\right.$ : E0-P28) for waves I-IV in response to tone bursts and for waves III and IV in response to clicks. In general, the overall picture is similar to that observed in developing $+/$ hyt animals (Sprenkle et al. 2001b).

The extent to which threshold differences contributed to latency prolongation in affected animals was estimated by comparing the form of latency-intensity curves expressed in sensation level terms, among groups, as shown in Figure 10 for the $20-\mathrm{kHz}$ condition. Although latency differences near threshold are apparent, with latencies of all four waves prolonged in the $\mathrm{T}_{4}$ : E0-E21 group relative to the $\mathrm{T}_{4}$ : $\mathrm{E} 0-\mathrm{P} 28$ group, differences were only significant for wave I, and these differences disappeared for all waves when intensity was raised to a level approximately $30 \mathrm{~dB}$ above threshold. Similar trends were observed for click-evoked and 8-kHz-evoked responses, indicating that threshold was only one of the factors affecting latency prolongation among animals that were treated for only a portion of the study period.

ABR interpeak intervals. Interpeak intervals (I-II, IIIII, and III-IV) and central conduction times (I-IV interval) measured as a function of stimulus level did not differ among the three groups of mice that received $\mathrm{T}_{4}$ throughout prenatal life. However, greatly prolonged mean intervals at $90 \mathrm{~dB}$ SPL were observed in untreated animals $\left(\mathrm{No} \mathrm{T}_{4}\right)$ and intermediate intervals were measured in those receiving thyroxin replacement only during the postnatal period $\left(\mathrm{T}_{4}\right.$ : $\left.\mathrm{P} 0-\mathrm{P} 28\right)$ (Fig. 11).

ABR wave amplitudes. The relative importance of thyroxin as a maturational agent affecting auditory system development, and peripheral function in particular, in the latter half of the first month is apparent when even casually inspecting click-evoked amplitudeintensity plots in Figure 12. While amplitudes are highly variable, it is relatively clear that responses were generally more robust in animals treated throughout the study period relative to either partial replacement condition, particularly for waves I and IV. It is equally clear that threshold improvement is the singular most dramatic parameter change associated with thyroxin treatment during the last half of the first postnatal month. Wave II was strikingly nonmonotonic in fully treated animals, but the nonmonotonicity was absent from the records of partially treated animals, presumably a reflection of high thresholds in those groups. Similar observations were made for amplitudeintensity functions generated from responses to 20 and $8 \mathrm{kHz}$.

Although variable from condition to condition, the 


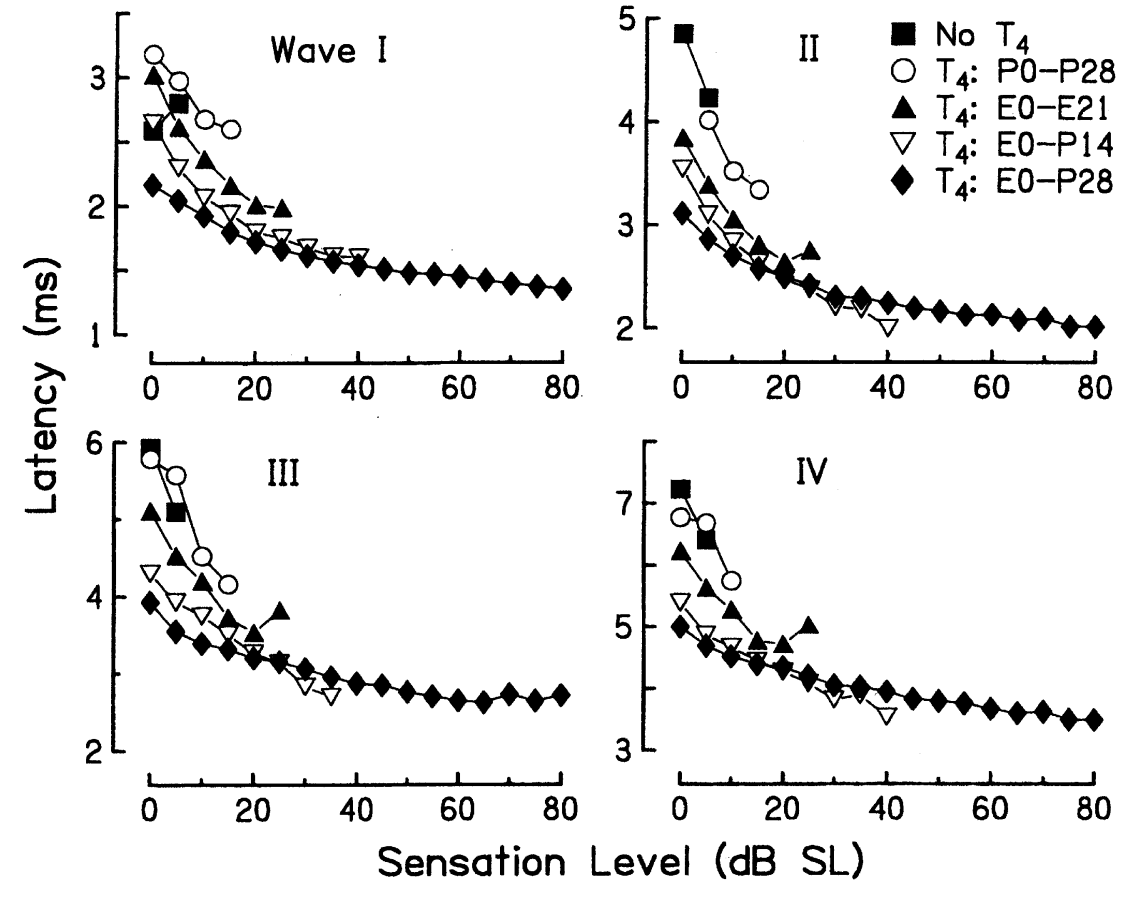

FIG. 10. Latency-sensation level functions in placebo- and thyroxin-treated mice. Mean latencies of ABR waves I-IV for each experimental group are plotted as a function of sensation level in response to $20-\mathrm{kHz}$ tone bursts. (Symbol key for all panels is shown in the upper-right panel.) Sensation level was computed by subtracting the $A B R$ threshold of each individual from the absolute sound pressure level. Means are shown for only two or more values at a given stimulus condition, except for the $\mathrm{No}_{4}$ and $\mathrm{T}_{4}$ : P0-P28 groups, for which means from all responses are included.

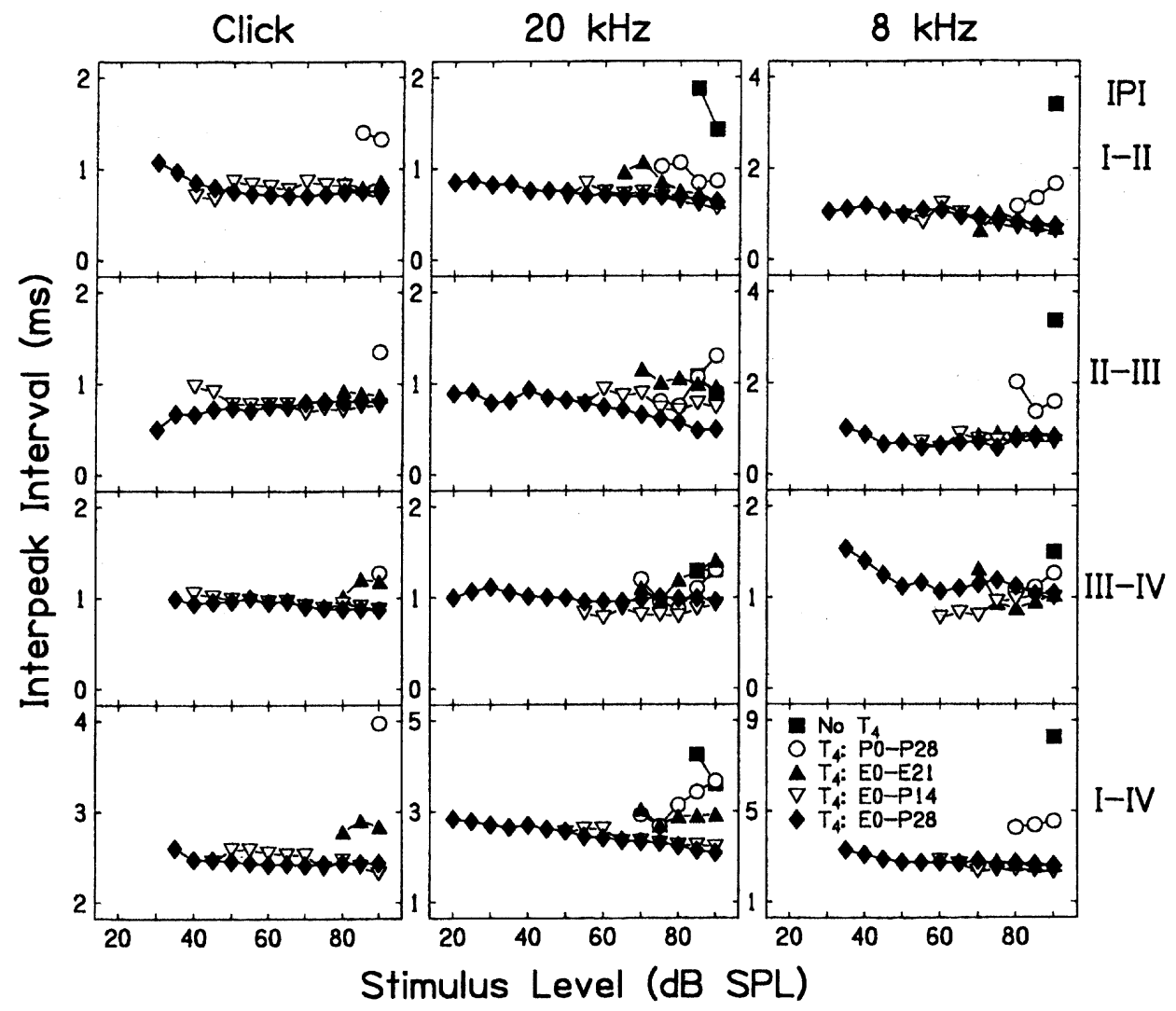

FIG. 11. Comparison of interpeak interval-vs-level curves in placeboand thyroxin-treated mice. Mean interpeak intervals between the first four ABR waves (I-II, II-III, and III$\mathrm{IV}$, top three rows) and central conduction time (wave I-IV interval, bottom row) for each experimental group are plotted as a function of stimulus level for clicks (left column), $20 \mathrm{kHz}$ (middle column), and $8 \mathrm{kHz}$ (right column). (Symbol key for all panels is located in the lowerright panel.) Means are shown for only two or more values at a given stimulus condition, except for the No $\mathrm{T}_{4}$ and $\mathrm{T}_{4}$ : P0-P28 groups for which means from all responses are included. cumulative effect of treatment duration is relatively clear in a composite plot of average amplitude-level curves representing responses to clicks, $20 \mathrm{kHz}$, and $8 \mathrm{kHz}$ (Fig. 13). Again, the importance of prenatal thyroxin is apparent in that members of both untreated groups (No $\mathrm{T}_{4}$ and $\left.\mathrm{T}_{4}: \mathrm{P} 0-\mathrm{P} 28\right)$ were either unresponsive or barely responsive to clicks or tone bursts, even at the highest stimulus levels used in the 


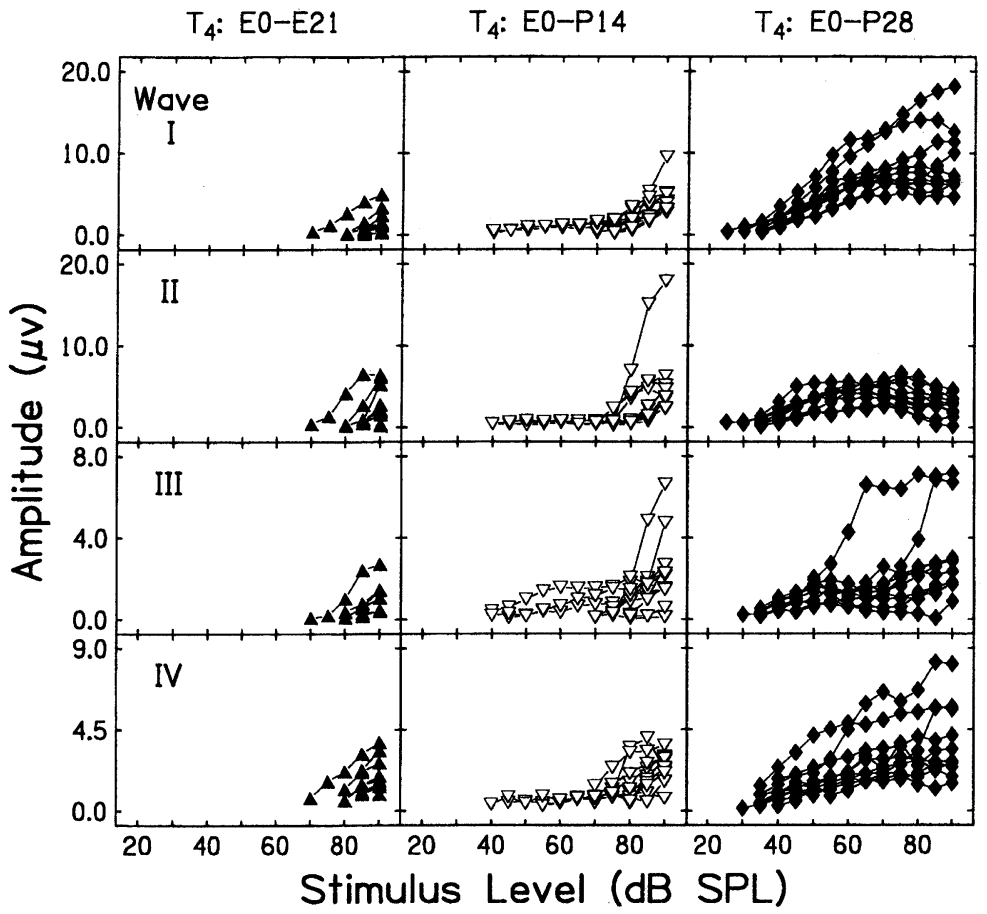

FIG. 12. Amplitude-level functions of thyroxin-treated mice. Click-evoked amplitudes for ABR waves I-IV (top to bottom rows) are plotted as a function of stimulus level for three of the experimental groups (columns). Each curve represents the responses of one individual.

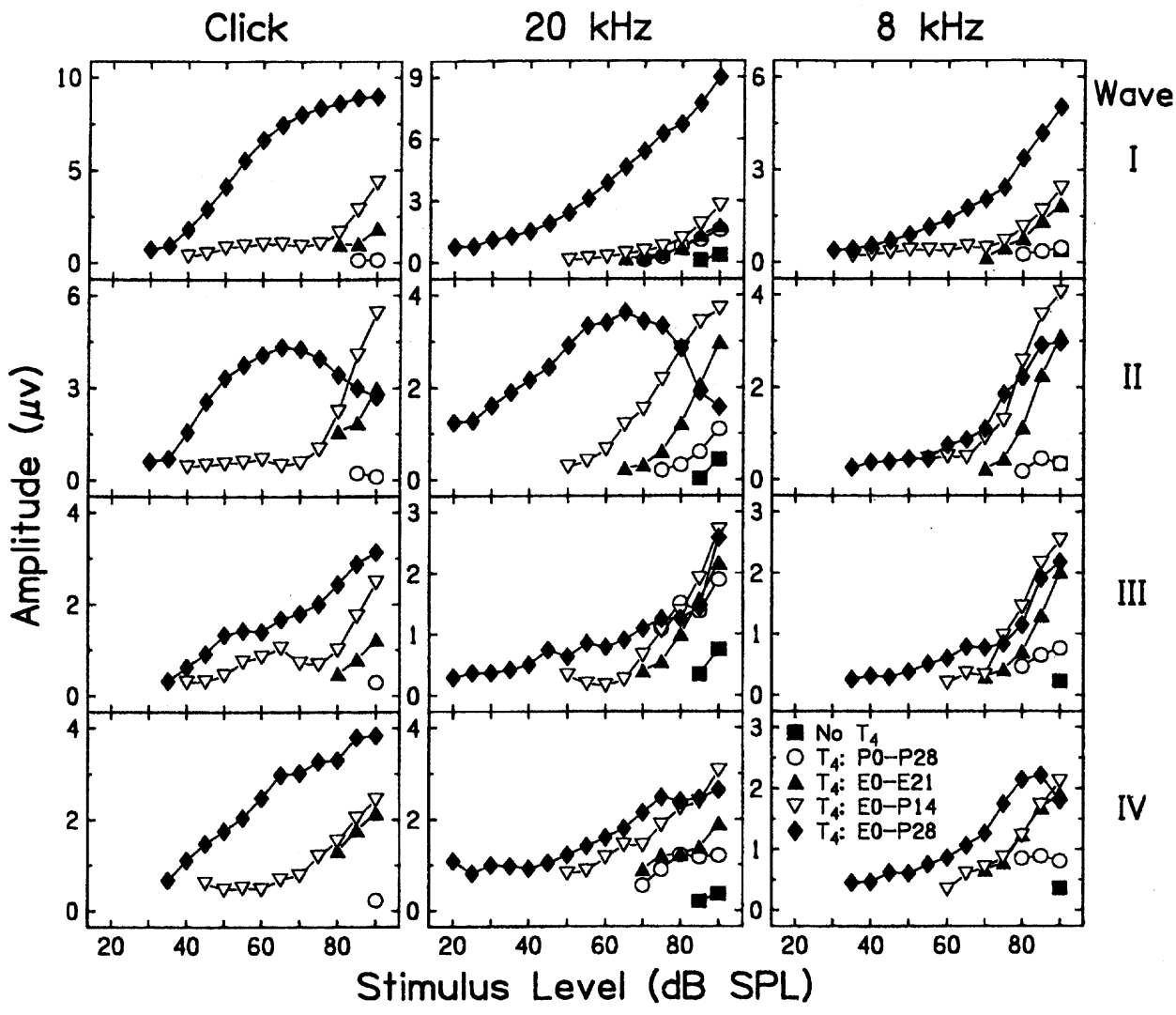

FIG. 13. Effects of thyroxin treatment on amplitude-level functions. Mean amplitudes of $\mathrm{ABR}$ waves I-IV (top to bottom rows) for each responsive group are plotted as a function of stimulus level for clicks (left column), $20 \mathrm{kHz}$ (middle column), and $8 \mathrm{kHz}$ (right column). (Symbol key for all panels is shown in the lower-right panel.) Means are shown for only two or more values at a given stimulus condition, except for the $\mathrm{NoT}_{4}$ and $\mathrm{T}_{4}$ : $\mathrm{P0}-\mathrm{P} 28$ groups for which means from all responses are included. study. The other remarkable finding revealed in average amplitude plots, like those shown here, is the relative importance of thyroxin beyond the second postnatal week. This is illustrated most dramatically for responses to clicks (left column), although the finding holds for the other stimulus conditions as well.

At $90 \mathrm{~dB}$ SPL the effect of postnatal treatment duration on response amplitude was most notable for wave 
I. The average amplitude of wave I in animals treated throughout the study period was more than twice that measured in mice whose treatment was discontinued on $\mathrm{P} 14\left(\mathrm{~T}_{4}: \mathrm{E} 0-\mathrm{P} 14\right)(p<0.001)$ and four times that measured for the prenatal group for most stimulus conditions.

\section{DISCUSSION}

The principal finding of this study is that peripheral auditory dysfunction can be prevented in the genetically hypothyroid hyt/hyt mouse by the exogenous administration of thyroxin from the time of conception through the end of the first postnatal month. It confirms the earlier suggestion of Sprenkle et al. (2001a) that normal hearing in hyt mice requires that thyroxin be delivered beyond the onset of hearing and extends that observation to affirm that the hormone is required throughout the period of cochlear development. A second major finding of this study is that the postnatal administration of thyroxin to prenatally hypothyroid homozygotes is largely ineffective.

$\mathrm{T}_{4}$ deficiency is the major cause of auditory abnormalities in homozygotes

In a companion study (Sprenkle et al. 2001a), we confirmed the observation of Deol (1973) that auditory dysfunction in hypothyroid mice born to euthyroid dams could be partially blocked by treating animals with thyroxin during the first 10 postnatal days of life. The rationale underlying that study was based on the historical perspective that a thyroxin-dependent critical period of development occurs in neonates prior to the onset of hearing in the mouse (Deol 1973). Deol observed that mice treated with thyroxin after postnatal day 0 develop essentially normal cochlear anatomy and suggested that the sensitivity of the auditory system to thyroid hormones declines following the attainment of cochlear function, which in the mouse occurs from P9 to P14 (Alford and Ruben 1963; Kikuchi and Hilding 1965; Mikaelian and Ruben 1965). However, two separate sets of data collected in the series of experiments reported here support the notion that sensitivity to thyroid hormone extends beyond the middle of the second postnatal week in the hyt mouse.

First, and perhaps most important, although exogenous thyroxin protected homozygous pups born to heterozygous dams from hypothyroid-induced dysfunction when administered between birth and P10, the protection was at best partial (Sprenkle et al. 2001a). That finding naturally led to the current study, and, based on results shown here, we are able to unequivocally state that thyroxin is an essential factor in auditory development beyond P14.

This finding should not be particularly surprising in light of the fact that notable cochlear development continues well beyond the age that airborne sounds first elicit detectable responses from the auditory system (Kraus and Aulbach-Kraus 1981; Shnerson et al. 1982). It is entirely reasonable to assume that thyroid hormones may be required for these late-stage events in cochlear differentiation. Given the fact that the organ of Corti is essentially adultlike after P14, one is drawn to consider the possibility that the efferent olivocochlear system may be especially important as a maturational factor during this late period since it is one of the last features of the system to organize (Lenoir et al. 1980; Shnerson et al. 1982; Simmons et al. 1998).

Prenatal $\mathrm{T}_{4}$ contributes significantly to hearing development

Traditionally it was held that thyroid hormones do not play a role in the development of audition during the prenatal period that preceded autonomous thyroxin secretion. Until recently, convincing evidence that maternal hormones are transported across the placenta or that fetal thyroid hormone receptors are expressed early enough to effect development was unavailable. This was true even though the devastating consequences of maternal iodine deficiency on fetal brain development were well documented (Delange 1991). With the discovery that significant amounts of maternal thyroxin are taken up by the fetal brain (Porterfield and Hendrich 1992), combined with the discovery that thyroid hormone receptors are expressed in both the brain (Pérez-Castillo et al. 1985) and cochlea (Bradley et al. 1994) well before the onset of autonomous fetal secretion, the issue is being revisited.

The findings reported here add to a body of evidence supporting the view that maternal thyroid hormones play an important role during development of the central and peripheral auditory systems, particularly when fetal thyroid hormone production is impaired. But what about earlier stages of development? The thyroid hormone receptors TR $\beta 1$ and $\mathrm{TR} \beta 2$ are expressed very early in inner-ear organogenesis and explicitly in the anlagen of the cochlea, while $\mathrm{TR} \alpha$ is expressed throughout the statoacoustic end organ (Bradley et al. 1994). This early expression, an event that occurs long before the system is responsive to sound, clearly points to the notion that inner-ear tissues contain thyroxin-responsive genes that are responsible for morphogenesis. Interestingly, however, cochlear malformations, including innervation patterns, are not observed in mice with null mutations 
in the gene encoding $\operatorname{TR} \beta$, even though affected animals are hearing-impaired (Forrest et al. 1996). Based on that observation, Forrest et al. suggests that the $\beta$ form of the $\mathrm{T}_{3}$ receptor controls functional maturation of the inner ear and the $\alpha$ form affects morphogenesis. By functional maturation, these authors presumably refer to thyroxin's capacity to regulate protein expression and thereby affect sensory mechanisms associated with mechanoelectrical transduction. However, auditory brainstem response thresholds are normal in mice with null mutations associated with $\operatorname{TR} \alpha$ and $\operatorname{TR} \beta 2$ (Rüsch et al. 1998; Abel et al. 1999), suggesting that cochlear development is not dependent on the activation of those signaling channels and raising the question, precisely what inner-ear tissues are effected by thyroid hormone? While precise $T_{3}$ targets in the embryonic ear are unknown, their identification will clearly promote a more comprehensive understanding of the mechanism(s) whereby thyroid hormones regulate auditory gene expression. The availability of the hyt mouse may facilitate that effort.

\section{ACKNOWLEDGMENTS}

This project was supported by grants from the Deafness Research Foundation and the NIH (DC01007, DC00215, DC00982).

\section{REFERENCES}

Abel Ed, Boers me, Pazos-Moura C, Moura E, Kaulbach H, Zakaria M, LOWEll B, RAdOVICK S, Liberman MC, WONDisford F. Divergent roles for thyroid hormone receptor $\beta$ isoforms in the endocrine axis and auditory system. J. Clin. Invest. 104:291300, 1999.

Adams PM, Stein SA, Palnitkar M, Anthony A, Gerrity L, SHANKLIN DR. Evaluation and characterization of the hypothyroid hyt/hyt mouse. I: Somatic and behavioral studies. Neuroendocrinology 49:138-143, 1989.

Alford BR, Ruben R. Physiological, behavioral, and anatomical correlates of the development of hearing in the mouse. Ann. Otolaryngol. 72:237-247, 1963.

BRAdley DJ, TOWLE HC, Young WS III. $\alpha$ and $\beta$ thyroid hormone receptor (TR) gene expression during auditory neurogenesis: Evidence for TR isoform-specific transcriptional regulation in vivo. Proc. Natl. Acad. Sci. USA 91:439-443, 1994.

DeLANGE FM. Endemic cretinism. In: Braverman LE, Utiger RD, (eds). The Thyroid, 6th ed. JB Lippincott Philadelphia, 1991, 942-955.

DEOL MS. An experimental approach to the understanding and treatment of hereditary syndromes with congenital deafness and hypothyroidism. J. Med. Genet. 10:235-242, 1973.

Dubois JD, Dussault JH. Ontogenesis of thyroid function in the neonatal rat. Thyroxine $\left(\mathrm{T}_{4}\right)$ and triiodothyronine $\left(\mathrm{T}_{3}\right)$ production rates. Endocrinology 101:435-441, 1977.

EHRET G. Development of absolute auditory thresholds in the house mouse (Mus musculus). J. Am. Audiol. Soc. 1:179-184, 1976.
Forrest D, Erway LC, NG L, Altschuler R, Curran T. Thyroid hormone receptor $\beta$ is essential for development of auditory function. Nature Gen. 13:354-357, 1996.

HÉbert R, LANGlois J-M, Dussault JH. Effect of graded periods of congenital hypothyroidism on the peripheral auditory evoked activity of rats. Electroencephalogr. Clin. Neurophysiol. 62:381387, 1985a.

Hébert R, Langlois J-M, Dussault JH. Permanent defects in rat peripheral auditory function following perinatal hypothyroidism: Determination of a critical period. Dev. Brain Res. 23:161-170, $1985 b$.

JACOBSON AG, BRENT RL. Radioiodine concentration by the fetal mouse thyroid. Endocrinology 65:408-416, 1959.

KiKUCHI K, HiLding DA. The development of the organ of Corti in the mouse. Acta Otolaryngol. 60:207-222, 1965.

Kraus H-J, Aulbach-Kraus K. Morphological changes in the cochlea of the mouse after the onset of hearing. Hear. Res. 4:89$102,1981$.

Lenoir M, Shnerson A, Pujol R. Cochlear receptor development in the rat with emphasis on synaptogenesis Anat. Embryol. 160:253-262, 1980 .

MEYERHOFF WL. Hypothyroidism and the ear: Electrophysiological, morphological, and chemical considerations. Laryngoscope 89:125, 1979.

MikAelian D, RUbEn R. Development of hearing in the normal CBA$\mathrm{J}$ mouse. Correlation of physiologic observations with behavioral responses and with cochlear anatomy. Acta Otolaryngol. 59:451461,1965

O'Malley BW, Jr. Li D, Turner DS. Hearing loss and cochlear abnormalities in the congenital hypothyroid (hyt/hyt) mouse. Hear. Res. 88:181-189, 1995.

Pérez-Castillo A, Bernal J, Ferreiro B, Pans T. The early ontogenesis of thyroid hormone receptor in the rat fetus. Endocrinology 117:2457-2461, 1985.

PORTERFIELD SP, HENDRICH CE. Tissue iodothyronine levels in fetuses of control and hypothyroid rats at 13 and 16 days gestation. Endocrinology 131:195-200, 1992.

Rüsch A, Erway LC, Oliver D, Vennstrom B, Forrest D. Thyroid hormone receptor $\beta$-dependent expression of a potassium conductance in inner hair cells at the onset of hearing. Proc. Natl. Acad. Sci. USA 95:15758-15762, 1998.

Shnerson A, Devigne C, Pujol R. Age-related structural changes in the C57BL/6J mouse cochlea. II. Ultrastructural findings. Dev. Brain Res. 2:77-88, 1982.

Simmons DD, Bertolotto C, Kim J, Raji-Kubba J, Mansdorf N. Choline acetyltransferase expression during a putative developmental waiting period. J. Comp. Neurol. 397:281-295, 1998.

SPRENKLE PM, (1997) The Auditory Brainstem Response (ABR) of the Genetically Hypothyroid (hyt/hyt) Mouse. Doctoral dissertation, Creighton University, Omaha, NE.

Sprenkle PM, McGee J, Bertoni JM, Walsh EJ. Consequences of hypothyroidism on auditory system function in Tshr mutant (hyt) mice. J. Assoc. Res. Otolaryngol. 2001a, DOI: 10.1007/ s101620010076.

Sprenkle PM, McGee J, Bertoni JM, Walsh EJ. Development of auditory brainstem responses (ABRs) in Tshrmutant mice derived from euthyroid and hypothyroid dams. J. Assoc. Res. Otolaryngol. 2001b, DOI: 10.1007/s101620010077.

Uziel A, Legrand C, Ohresser M, Marot M. Maturational and degenerative processes in the organ of Corti after neonatal hypothyroidism. Hear. Res. 11:203-218, 1983.

Uziel A, Marot M, Rabie A. Corrective effects of thyroxine on cochlear abnormalities induced by congenital hypothyroidism in the rat. II. Electrophysiological study. Brain Res. 351:123-127, 1985 .

VAN HEYNINGEN HE. The initiation of thyroid function in the mouse. Endocrinology 69:720-727, 1961. 